\title{
THE SHORT-TERM SOCIAL IMPLICATIONS FOR CONSTRUCTION WORKERS OF INTRODUCING ROBOTS ONTO AUSTRALIAN BUILDING SITES
}

\author{
C.C. Neil, G.D. Salomonsson and R. Sharpe \\ Commonwealth Scientific and Industrial Research Organisation \\ Division of Building, Construction and Engineering \\ P.O. Box 56, Highett, Victoria 3190, Australia
}

\begin{abstract}
This paper examines some of the short-term social implications for workers of introducing robots onto Australian construction sites. Consideration is given to their possible consequences for job displacement and job loss, polarisation of the work force, workers' job satisfaction, the loss, retention and enhancement of workers' skills, and union disputation. The discussion suggests that the successful introduction of robots will depend largely on timing, implementation procedures, and appropriate job design for operators. However, it has some implications for robot design: the design and development of single-purpose robots that assist an operator carry out a task best fits the characteristics of the industry at the present point in time.
\end{abstract}

\section{INTRODUCTION}

This paper examines the possible social implications for construction workers of introducing robots onto Australian building sites.

Any predictions of the outcome of a new technology are inevitably highly speculative. However, unless the initial introduction of robots takes into account the consequences for the work force, problems are likely to ensue. If the potential consequences are understood, then it may be possible to maximise the favourable outcomes, and minimise the unfavourable ones, by:

(a) modifying existing robotic design;

(b) placing an emphasis at different stages of robot development on the design of robots with the type of man-machine interaction that best fits the characteristics of the industry at that particular point in time; and/or

(c) evolving an appropriate job design for robot operators.

Having explored some of the potential social consequences of the robotisation of construction sites, the paper concludes by looking at their implications for robot design and implementation tactics.

\section{THE DATA}

It was originally proposed that the information for this study would come from structured interviews with construction managers and workers. Interviews were carried out with 118 managers from major contracting companies and specialist subcontracting companies in Melbourne and Sydney (for sampling details, see ref. (1)). These interviews were supplemented by a survey of 53 construction site workers. Site circumstances precluded both a random selection of site workers and the interviewing of a larger sample. The workers' responses cannot be assumed to be representative of all construction workers, but they provide some insight into the attitudes of construction tradesmen and labourers. 
It became clear during the interviews that few of the managers or workers had any knowledge of overseas developments in robotics. As a result, tabulation of the answers to the structured questions had little meaning. The structured questions did, however, stimulate a lot of discussion. This paper is based on the synthesis of the views expressed in these discussions, and overseas literature on the impact of automation.

\section{POTENTIAL SOCIAL IMPLICATION OF INTRODUCING ROBOTS}

The outcome of introducing robots into an industry is by no means automatic: 'the characteristics of the technology, the manner in which robots are introduced, the organisation's structure, and the people who work in the organisation [all] determine the impact of robotics' (2). In Australia, four key characteristics of the construction industry are relevant to the social outcome of robotisation.

(a) Boom and bust conditions are an inherent feature, and are potentially exacerbated by the extent of foreign investment in the building industry.

(b) Work is highly specialised, both at the company level and the individual worker level. Major contractors usually employ only a small percentage of the onsite work force, and tender much of their work to specialist subcontractors. In 1989, specialist subcontractors represented 76 per cent of all residential and non-residential construction establishments in the industry (3). These firms employed less than five people on average. The use of subcontractors means that major companies invest in relatively little plant of their own. The purchase of robots, therefore, is likely to fall to the larger of the subcontractors.

(c) 'Sections of the building industry can be shown to have had, in recent years, one of the worst industrial relations climates of any industry, of any country' (4). The cyclical nature of building, the temporary nature of construction sites, and the limited scope for establishing stable working relationships, all make industrial relations particularly difficult (5). Further, because of the reliance on subcontractors, loyalty between the work force and major contractors is limited.

(d) Several large unions are usually involved in major projects. Demarcation is important to the unions as a means of protecting their members' jobs, the professional standards of the trade vested in their members, and their union membership levels. Although some restructuring is currently taking place, there appears to be little movement towards multiskilling.

The initial introduction of robots onto construction sites has a number of potential implications for the worker. First and foremost, there is the question of job loss or job displacement. Robotisation is also likely to have implications for:

(a) polarisation of the work force;

(b) workers' job satisfaction and self-image;

(c) loss, retention and enhancement of skill levels among workers in the industry;

(d) the relative control managers and workers are able to exercise over who does what when, and at what pace; and

(e) levels of industrial disputation.

Each of these issues is discussed in turn below.

\subsection{Job Displacement and Job Loss}

The boom and bust conditions in the industry inevitably lead to peaks and troughs in labour supply and demand. In the past, there have been 'severe, periodic shortages in the building trades... coinciding with booms in construction' (6). 
A number of the managers interviewed believed that the introduction of robots would help meet the increased demand for skilled labour that occurs in boom times, and thereby also reduce the excess supply of labour that occurs in down times. However, if robotised, the industry would still require a fluctuating number of workers skilled in robot programming (by this we mean supervision, planning and scheduling, rather than just low level computer programming) and maintenance, although these skills are likely to be more adaptable from industry to industry than are specialised craft skills. In 'bust' times, it is unlikely that it will be possible to bring robots on and off stream as quickly as labour. Indeed, given the high capital cost of robots, companies are unlikely to be prepared to have robots idle when they can lay off labour. Thus, robots are unlikely to even out peaks and troughs in labour demand.

The concern of the unions is less with smoothing out peaks and troughs, than with overall job loss or displacement. In the long term, the likelihood of automation of construction leading to a major loss of jobs in the economy as a whole is debatable. In the short term, the introduction of new technologies leads to the disappearance of some or all of the tasks involved in certain jobs. This can lead to job loss for existing workers in a newly automated industry through either an absolute loss of jobs to the industry or through a redistribution of the jobs within the industry (the jobs of tradesmen, for example, being displaced to those white-collar workers who already have certain skills such as computing programming).

\subsection{Polarisation of the Construction Labour Force}

Even if job loss or displacement is avoided, there is still a danger that robotisation could lead to the polarisation of the work force into a dual structure with some workers forming a specialised élite (7).

The danger of polarisation is aggravated in Australia by the number of non-English speaking workers in construction. Since the 1940 s, immigration has been used to alleviate labour shortages during boom periods (6). This has led to major language barriers on sites. Given the problems that language barriers present to training, there is a danger that only a segment of the present construction work force may be retrained to use robots. This problem could be exacerbated by the fact that those with language difficulties tend to be concentrated:

(a) on central business district sites, which have the type of work that most lends itself to robotisation; and

(b) in those companies which employ the largest proportion of 'permanent' workers, and therefore have the most to gain from retraining.

Further, specialisation in the industry means that subcontractors will be the first to purchase robots. If subcontractors who purchase robots then become specialists in their use, polarisation of the work force could be difficult to avoid.

\subsection{Workers' Job Satisfaction}

There are certain areas where robots are likely to be welcomed by all concerned. These include both highly dangerous and unpleasant work. In other areas there may be less convergence in the reactions to robotisation. For example, there may be a significant number of fatal falls each year by workers on multistorey buildings. When faced with the introduction of a robot that can do high-rise work, however, the safety element may be less salient to the construction worker than the question of job security, especially since jobs with a strong danger element are one of the few sources of high income open to a semiskilled worker at an early age.

A study of the social implications of the introduction of robotics into the German manufacturing industry showed that both physical and environmental strain were significantly reduced, but the 
need for robot operators to work at a fixed rhythm, and often in social isolation, introduced new sources of strain (8). Other studies have shown that occupational experiences such as closeness of supervision, routinisation and lack of complexity in the tasks carried out - that is, experiences that might come with automation - tend to be associated with reduced satisfaction.

Such changes in job characteristics will not necessarily occur in the unstructured work environment of an Australian building site. Even if they were to occur, their impact on the workers' job satisfaction would not be determined by the changes alone. Factors such as age, gender, experience, seniority and personal work values have all been shown to influence workers' reaction to different characteristics of their job. Workers, moreover, adapt to their work environment. The importance attached to job characteristics not generally associated with a particular occupation tends to decline among those in that occupation (9).

Simply examining changes in job characteristics that might occur with robotisation, will not, therefore, indicate the impact that automation might have on job satisfaction. For example, concepts of masculinity in the workplace change in adaptation to changing working conditions (see, for example, refs (10) and (11)). Working with the latest sophisticated technology may boost a male worker's self-image, and thereby his job satisfaction. Alternatively, retraining may undermine his self-image, as valued skills change from those involving physical prowess and skills learnt as a result of long experience in the trade.

There are a number of dimensions to job satisfaction. The range and relative importance of these for different groups of workers would need to be studied in detail and in context before attempting to predict the full impact of robotisation. However, the workers' interviews so far have given some indications of possible impacts.

Variety, both in projects undertaken and in tasks performed, was highly valued by most construction workers. If robotisation reduced the variety of tasks that certain workmen undertook, dissatisfaction could follow.

Autonomy did not appear to be valued greatly. This may be because those who wish to exercise autonomy are able to do so, and therefore take it for granted. Alternatively, a decline in the value attached to autonomy may be the result of an increased emphasis on close onsite supervision to pick up mistakes. If the latter is the case, any loss of autonomy may have little impact on job satisfaction.

There was little to indicate that construction workers valued a 'macho' self-image that might lead to a pride in doing dangerous work, and, therefore, a reluctance to accept a machine that might remove danger. Construction workers' pride in their work for the most part comes from seeing a high quality finished building, and feeling that they had had a part in its creation - the more so if they had been able to invest a high level of skill in the project themselves. It was generally agreed that this pride would remain unchanged if the part played by the worker had been the operation of a robot.

The interviews did suggest two possible sources of threat to job satisfaction from robotisation. The first is the possible increase in prefabrication that robotisation could bring. The majority of workers interviewed disliked the idea of working in a prefabrication plant. Offsite prefabrication work was seen as quick and unreliable, repetitive, rigid, confined and lacking in variety. Work in a prefabrication plant was seen as excluding outdoor work, for which the men expressed a definite preference.

The second threat to job satisfaction that could come from robotisation is deskilling. The use of skills was a significant component of job satisfaction for many of the workers interviewed.

\subsection{Loss, Retention and/or Enhancement of Skill Levels among Workers in the Industry}

Job enhancement has been observed in some industries when robots have been introduced. It is often believed, however, that automation will lead to deskilling. 
Discussions of the relationship between robotics and deskilling are rarely based on a welldefined concept of skill. There are several different conceptions of skill. These do not necessarily overlap. Firstly, the concept of skill can refer to the complex set of task-related abilities which are developed within a particular occupation. Since these abilities are objective, they can clearly be assessed. Secondly, the concept can refer to control over the labour process - that is, control over who does what, when and at what pace. Thirdly, it can refer to conventional definitions of occupational status (12).

The first two concepts need to be clearly separated when considering the possible relationship between automation, deskilling and skill enhancement.

\subsubsection{Skill enhancement, deskilling and objective abilities}

A decline in the use of task-related abilities by the construction work force has been occurring for some time. The practice in boom periods of upgrading semiskilled workers to trades level positions after a relatively short period of on-the-job training has spread with the growth of subcontracting and increased use of modular construction techniques (6). This practice has been fuelled by the fact that apprenticeships appear to be too long and too inflexible to cope with the changing conditions of a boom and bust industry. Further deskilling has arisen because only a narrow range of the skills that a worker acquires are often now used - a function partly of the specialisation of labour and partly of the subcontracting system. Innovations in products such as adhesives have had the same result.

Managers and union representatives interviewed were divided in their opinion whether robots were likely to continue this process of deskilling. Some managers felt that in the long term, robotisation would lead to a loss of traditional abilities. Others felt that there would be sufficient need to practise existing trade skills in situations not appropriate for robotisation (for example, in the construction of domestic homes) for such skills to be preserved.

Few of the managers interviewed, however, felt that there would be an overall net deskilling of construction labour. Those who felt that there might be an loss of traditional abilities said that the latter would be replaced by new abilities associated with programming and maintaining robots. Indeed, some felt that the coupling of the physical capacity and accuracy of robots with human judgment may increase the worker's ability to perform at a consistent level of skill throughout his or her working life, rather than peaking at an early age, then declining in performance with a decline in physical strength, dexterity or perhaps 'nerve'.

Union representatives interviewed welcomed the above possibility, but were deeply concerned that the acquisition of new skills would pass to a different segment of the work force.

\subsubsection{The relative control exercised by managers and workers}

The second concept of deskilling - control over who does what, when, and at what pace has provided the focus for extensive debate in recent literature (see, for example, ref. (13)). In the 1960 s and early 1970s, it was assumed that automation would lead to rising skill and responsibility among workers, and the blurring of manual/white-collar distinctions. By the late $1970 \mathrm{~s}$, automation was seen as leading to deskilling, and the transfer of the knowledge associated with craft skills into management hands. Control of how work is done and at what pace was also seen to pass to management with this transfer of knowledge (14).

Robotisation could be used by managers in the construction industry to try to increase their control over labour (for examples of the use of automation to increase managerial control, see ref. (15)). The inevitability of this, however, is questionable (see, for example, refs (13), (16)-(18)).

Firstly, the assumption that automation will inevitably increase managerial control is based on an inappropriate zero-sum concept of control (19). Worker control over the more immediate 
aspects of production may increase simultaneously with management control over the process. Workers "simply" lose the advantage of management ignorance' (19). Perhaps a more realistic scenario, in the case of robotisation, is that both managers and workers alike might lose control over knowledge of the process, such knowledge resting with consultants or advisers outside the company (20).

Secondly, the assumption that automation will inevitably increase managerial control does not take into account the fact that mechanisation creates new skills, competencies and other opportunities for bargaining leverage (21). Crane drivers, for example, currently dominate many of the labour process decisions on Australian construction sites. Some managers feared that if only a small number of workers were trained in the use of robots, robot operators could achieve the same power that crane drivers now hold.

Thirdly, it cannot automatically be assumed that managers will wish to adopt a strategy designed to increase their control over the workers. The first priority of companies is to make profits, not to increase control (22). A recent study of the Australian construction industry (4) concluded that 'many employers in the industry have the attitudes that labour in the industry is disruptive, uncooperative and a problem to be overcome'. Nonetheless, only a few managers in our survey talked of the introduction of robots as something that could be used to gain more power or control over the workers. The fragmentation of the industry, moreover, means less pressure on many employers to exert control - the smaller size of employing companies leads to closer and more harmonious contact between bosses and workers on small jobs.

Fourthly, management is 'not omniscient, conspiratorial, and able always to get its own way ...product and labour markets, technology and trade unionism have independent roles in the process of struggle and negotiation which constitutes the labour process' (18). If managers were to seek to use automation to increase their control over labour, their chances of success would depend on:

(a) whether, at the time robots were introduced, there were alternative sources of employment with equal earning possibilities available to Australian construction workers;

(b) the extent to which government involvement in the industry and in industrial relations in the country would restrict the extent to which either management or workers were able to exert control over the other; and

(c) the extent to which divisions among the workers in the industry would be likely to reduce their power to organise.

With respect to the last constraint, the ability of Australian construction workers to organise sufficiently to resist increased managerial control is limited by:

(a) the short life of construction projects;

(b) the ethnic heterogeneity in the work force (which has been exploited by some managements in the United States to divide the labour force);

(c) the lack of a clear sense of class identity among construction workers. This lack arises both from the infrequency with which a critical mass of workers work together (23), and from the alternation of a significant number of skilled workers between external employment, selfemployment and the ownership of small subcontracting businesses. (The general pattern over the last ten years seems to have been that in boom times specialist subcontracting companies tend to grow in number rather than in size); and

(d) the strains on interunion cooperation that arise from demarcation disputes.

On the other hand, certain factors enhance construction workers' ability to resist increased managerial control: 
(a) Workers are already highly unionised. Potential barriers to organisation have already been overcome.

(b) Construction robots are not likely to undermine the existing organisation of labour. They are unlikely to isolate workers in the same way that increasing mechanisation in the mining industry, for example, has isolated some of its operators, who 'sit in [quiet] enclosed cabs or cockpits enveloped by noise' (23).

(c) A construction project is 'particularly vulnerable towards completion when considerable funds are committed. It is often cheaper for the employer to concede in a dispute rather than incur further holding costs' (5).

\subsection{Union Disputes}

A number of issues relating to robotisation will need to be resolved if the introduction of robots onto construction sites is not to result in major industrial disputation. Union demarcation rules may lead to several unions each claiming that the use of a robot which does several construction tasks should be restricted to their members. The introduction of any robot that could involve potential job loss or displacement to a union's members is likely to be strongly contested. Failure to reward construction workers for increases in productivity will also lead to conflict.

The danger of industrial disputation associated with robotisation, however, extends beyond the implications of robotisation itself. 'Because of the centralised wage fixing system in Australia it has been a successful tactic of unions...to concentrate on prominent building sites and get concessions which are then generalised across the industry' (4). The result is that central business district sites tend to experience the most lost time due to industrial disputes, and are most likely to be used by unions to get concessions that can be generalised across the industry (4).

This makes the introduction of robots particularly vulnerable to union disputation. The type of work most adaptable to the use of robots tends to be central business district work. Thus, the most promising sites for the use of robots are the sites that already experience the most industrial disputation. If the introduction of robots becomes a weapon in the process of adversarial industrial relations, there is a danger either of bans being placed on particular robots, or of disputes being resolved by restrictive specification of duties for the use of robots.

\section{CONCLUSION}

The successful introduction of robots onto Australian construction sites will depend on timing, implementation procedures, and the job design for robot operators. The most socially desirable application of robotics, from the workers' perspective, is to have each worker in charge of a combination of robotic and conventional equipment (7). Robot operators should be trained in programming and perhaps maintenance, and not just converted into machine minders. The timing of the introduction of robots will be very important for their acceptance: to introduce any machines that result in significant job loss or displacement when the industry is in recession could be considered not only irresponsible, but counterproductive. Above all, examination of the potential consequences of robotisation highlights the need for extensive union-management negotiations before any attempt is made to bring robots onto construction sites.

However, examination of the potential social consequences has at least two implications for the ongoing design and development of robots. Firstly, the structure of both the industry and industrial relations, at the moment, favours single-purpose robots. Secondly, the robots that are likely to be most acceptable to the industry at the moment are robots that assist in carrying out a task, rather than being autonomous. Robots that simply assist an operator seem unlikely to generate any significant job loss or displacement.

The introduction of robots should be a stepwise approach, with each stage progressively increasing the range of appropriate skills in the construction work force, and increasing the 
awareness and the realism of the expectations. If they can be demonstrated to be economically and technically feasible, there is no reason why robots of the type indicated above should not be introduced now.

Thus, the design and development of single-purpose robots to assist an operator carry out a task could have immediate applicability to the Australian scene, and pave the way for other robots in the future.

\section{REFERENCES}

1. Neil, C.C., Salomonsson G. and Sharpe, R. (forthcoming). Introducing Robotics into the Construction Industry: Realising Their Advantages. (CSIRO: Melbourne).

2. Argote, L. and Goodman, P.S. (1986). 'The Organizational Implications of Robotics'. In Davis, D.D. and Associates (eds), Managing Technological Innovation. (Jossey Bass Publishers: San Franscico).

3. Australian Bureau of Statistics (1990). Construction Industry Survey, Private Sector Establishment, 1988-89. Catalogue No. 8770. (Australian Bureau of Statistics: Canberra).

4. Ireland, V. (1988). Improving Work Practices in the Australian Building Industry: A Comparison with the UK and the USA. (Master Builders' Construction and Housing Association Australia: Turner, ACT).

5. Australia Industry Commission (1990). Draft Report on Construction Costs of Major Projects. (Australia Industry Commission: Canberra).

6. Department of Employment Education and Training (1989). The Building Trades in NSW. A Labour Market Assessment. (Department of Employment Education and Training: Sydney).

7. Kansai Productivity Center and National Institute for Research Advancement (1985). Mechatronics: The Policy Ramifications. (Asian Productivity Organization: Tokyo).

8. Wobbe-Ohlenburg, W. (1982). 'The Influence of Robots on Qualification and Strain'. Proceedings of the International Conference on Robots in the Automotive Industry, Birmingham, April 1982.

9. Kanter, R.N. (1977). Men and Women of the Corporation. (Basic Books, Inc.: New York).

10. Yarrow, M. (1986). 'Class and Gender in the Developing Consciousness of Appalachian Coal Miners'. Paper presented at UMIST/Aston Fifth Annual Conference on the Organization and Control of the Labour Process, Manchester, May 1986.

11. Baron, A. (1986). 'Technology and the Crisis of Masculinity: The Social Construction of Gender and Skill in the U.S. Printing Industry, 1850-1920'. Paper presented at UMIST/ Aston Fifth Annual Conference on the Organization and Control of the Labour Process, Manchester, May 1986.

12. Beechey, V. (1982). 'The Sexual Division of Labour and the Labour Process: a Critical Assessment of Braverman'. In Wood, S. (ed.), The Degradation of Work? Skill, Deskilling and the Labour Process. (Hutchinson: London). 
13. Thompson, P. (1983). The Nature of Work. An Introduction to Debates on the Labour Process. (MacMillan: London).

14. Braverman, H. (1974). Labor and Monopoly Capital: The Degradation of Work in the Twentieth Century. (Monthly Review Press: New York).

15. Shaiken, H. (1984). Work Transformed. Automation and Labour in the Computer Age. (Holt, Rinehart and Winston: New York).

16. Friedman, A.L. (1977). Industry and Labour: Class Struggle at Work and Monopoly Capitalism. (Macmillan: London and Basingstoke).

17. Edwards, R. (1979). Contested Terrain: The Transformation of the Workplace in the Twentieth Century. (Basic Books, Inc.: New York).

18. Wood, S. (ed.) (1982). The Degradation of Work? Skill, Deskilling and the Labour Process. (Hutchinson: London).

19. Wood, S. and Kelly, J. (1982). 'Taylorism, Responsible Autonomy and Management Strategy'. In Wood, S. (ed.), The Degradation of Work? Skill, Deskilling and the Labour Process. (London: Hutchinson).

20. Cheetham, A. and Woolliams, P. (1986). 'Robotic Based Manufacturing: The Socio-technical Concept'. Computer Bulletin, December.

21. Elger, T. (1982). 'Braverman, Capital Accumulation and Deskilling'. In Wood, S. (ed.), The Degradation of Work? Skill, Deskilling and the Labour Process. (Hutchinson: London).

22. Littler, C.R. and Salaman, G. (1987). 'Bravermania and Beyond: Recent Theories of the Labour Process'. Sociology 16: 251-69.

23. Yarrow, M. (1979). 'The Labor Process in Coal Mining: Struggle for Control'. In Zimbalist, A. (ed.), Case Studies in the Labor Process. (Monthly Review Press: New York and London). 